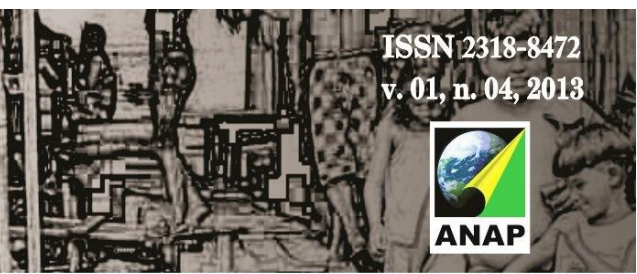

Título do Trabalho

\title{
GESTÃO COMPARTILHADA NA MANUTENÇÃO DOS ESPAÇOS PÚBLICOS DA CIDADE: UM OLHAR SOBRE A SUBPREFEITURA DE PINHEIROS EM SÃO PAULO.
}

Autor(a)

Roberta Laredo

Nome do(a) Orientador(a)

Nadia Somekh

Instituição ou Empresa

Universidade Presbiteriana Mackenzie

E-mail de contato

roberta.laredo@hotmail.com

Palavras-Chave

Gestão dos Espaços Públicos. Áreas Verdes Urbanas. Gestão Compartilhada.

1 INTRODUÇÃO

A importância dos espaços públicos ${ }^{1}$ vem crescendo juntamente com a necessidade de se criar lugares que possam trazer qualidade ambiental e tem sido incorporada no discurso dos diversos atores que compõe a sociedade. Essa importância se torna mais contundente à medida que o espaço público é reapropriado pela população como temos visto nas recentes manifestações espalhadas pelo país.

\footnotetext{
${ }^{1}$ Aqui entendidos, como os de prática social e reduzidos aos parques, praças, jardins e canteiros (áreas ajardinadas).
} 


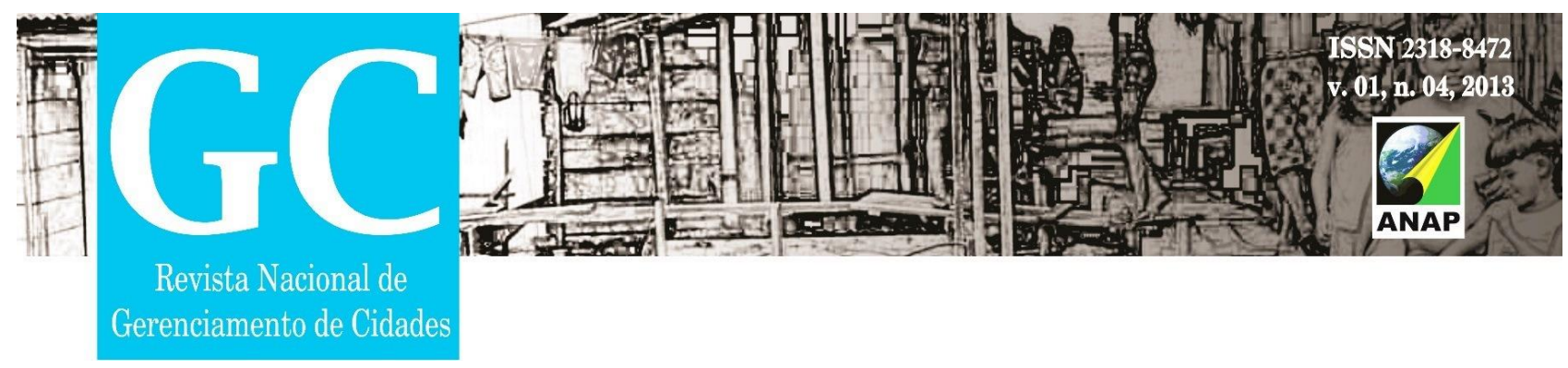

A função desses espaços, que se moldam de acordo com as transformações sofridas pela cidade é, portanto, representativa da sociedade e impactam, por sua vez, no estilo de vida da população.

François Ascher (2001) explica que estamos entrando em uma nova fase da contemporaneidade e, por isso, são necessárias transformações que nos levem a uma nova concepção do espaço e consequentemente da gestão desse novo território. Portanto, a sociedade "deve portar-se de novos instrumentos para tentar controlar essa revolução urbana, tirar partido dela e limitar seus eventuais prejuízos." (ASCHER, 2001, p.18).

Podemos entender que a necessidade de transformação e a crescente demanda por espaços públicos têm feito com que a prefeitura, por meio de políticas públicas, utilize instrumentos que deem maior atenção e aporte de recursos na manutenção dessas áreas. É o caso dos Termos de Cooperação ${ }^{2}$ que têm o objetivo de firmar parcerias com a sociedade para a execução e manutenção dos espaços públicos, conferindo a esses lugares melhorias urbanas, ambientais e paisagísticas.

Assim, a utilização dos Termos de Cooperação reflete o encolhimento dos orçamentos destinados à manutenção dos espaços públicos, mas também pode refletir uma nova estrutura social a qual François Ascher (2001) chama de estrutura social de redes. Essa estrutura tem um caráter de solidariedade comutativa, neste caso relacionando as pessoas e as organizações através de redes interconectadas, mas que, a exemplo do que aconteceu nas recentes manifestações, podem se expandir e se transpor para o espaço púbico, impondo então um novo desafio que é o de transformar essa solidariedade "reflexiva" em uma democracia que incorpore essa consciência de pertencimento a um sistema de interesse coletivo.

Entretanto, a apropriação dos espaços públicos não acontece se essas áreas não oferecerem elementos capazes de qualificar o ambiente. Segundo Gehl (2010), há uma

\footnotetext{
${ }^{2}$ Decreto № 52.062, de 30 de dezembro de 2010. Confere nova regulamentação ao artigo 50 da Lei no 14.223 , de 26 de setembro de 2006, o qual dispõe sobre a celebração de termos de cooperação com a iniciativa privada, visando à execução e manutenção de melhorias urbanas, ambientais e paisagísticas, bem como à conservação de áreas municipais, em consonância com o disposto no artigo 24 da Lei no 14.517, de 16 de outubro de 2007; acresce o § 3ํao artigo $2^{\circ}$ do Decreto $n^{\circ}$ 40.384, de 3 de abril de 2001, que dispõe sobre a doação de bens e serviços e 0 estabelecimento de parcerias com a iniciativa privada; revoga o Decreto № 50.077, de 6 de outubro de 2008.
} 


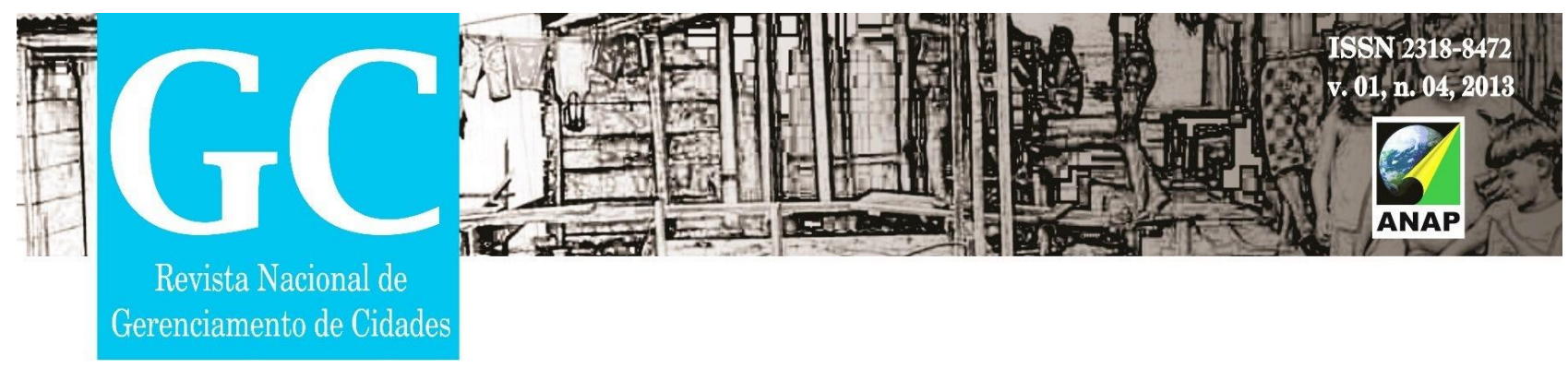

correlação direta entre a qualidade dos espaços e a fruição que eles geram. Bons espaços estimulam a permanência e aumentam as chances de contato entre as pessoas. Apesar de estar-se falando do desenho urbano como um todo, muitas vezes isso se traduz em detalhes como a limpeza e a manutenção, por exemplo.

\section{OBJETIVO GERAL}

O objetivo deste trabalho é apresentar um panorama atual da gestão dos espaços públicos desenvolvida pela prefeitura de São Paulo, especificamente na subprefeitura de Pinheiros.

\section{OBJETIVO ESPECÍFICO}

Identificar os espaços públicos que fazem parte da subprefeitura de Pinheiros verificando como se dá a apropriação das áreas que possuem Termos de Cooperação firmados entre subprefeitura de Pinheiros e a sociedade civil.

\section{METODOLOGIA}

A metodologia aplicada estruturou-se em três eixos:

- Inicialmente foram feitas visitas técnicas à subprefeitura de Pinheiros para levantamento de dados de áreas verdes, incluindo quantidade, projetos, mapas de localização e outros documentos que pudessem auxiliar na identificação do objeto estudado.

- Em seguida foram feitas entrevistas com a equipe técnica da subprefeitura para investigar os desafios da gestão desses espaços.

- Finalmente, os dados levantados e o resultado das entrevistas foram sistematizados de forma a atingir os resultados buscados.

\section{RESULTADOS}




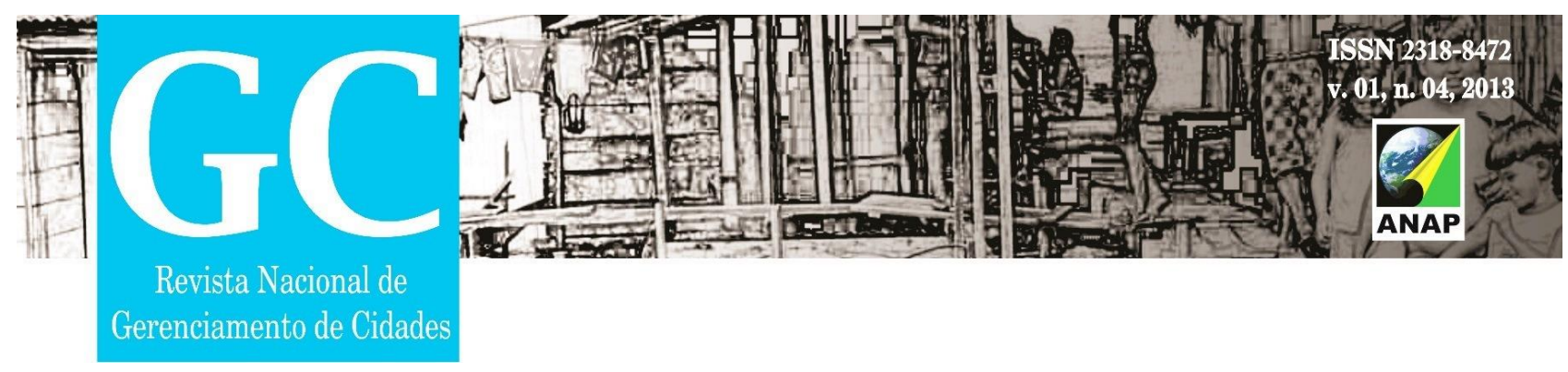

A prefeitura da cidade de São Paulo há muito persegue um modelo de gestão dos espaços públicos que, com exceção dos parques geridos pela Secretaria Municipal do Verde e Meio Ambiente (SVMA), é feita pelas subprefeituras.

No caso da subprefeitura de Pinheiros, atualmente existem três equipes de jardinagem e três equipes de corte e poda de árvores, gerenciadas pela unidade de áreas verdes, além de uma equipe de manutenção que cuida de passeios, equipamentos e mobiliários. A equipe de manutenção tem um acionamento mais esporádico, a equipe de jardinagem mais frequente; as equipes de corte e poda são acionadas quando necessário.

A Coordenadoria de Projetos e Obras, composta pela Supervisão de Projetos e Obras, Supervisão de Manutenção e Supervisão Técnica de Limpeza Pública, onde se encontra a Unidade de Áreas Verdes, são as divisões responsáveis pelos espaços públicos - incluindo-se aí ruas e áreas verdes na região da subprefeitura de Pinheiros. Entretanto, segundo o atual subprefeito, o arquiteto Angelo Salvador Filardo Junior ${ }^{3}$, a subprefeitura enfrenta um problema com a varrição e a limpeza dos canteiros, pois o serviço de varrição do município não tem responsabilidade com a limpeza e a equipe de manutenção dos canteiros também não tem a atribuição para limpá-los, fazendo com que essas áreas permaneçam frequentemente sujas, com aparência de abandono mesmo que estejam recebendo manutenção periódica.

Como forma de melhorar a gestão dos espaços públicos a prefeitura, em 2006, cria a Lei № 14.223, que dispõe sobre a ordenação dos elementos que compõem a paisagem urbana do Município de São Paulo e passa a contar com esse instrumento de parceria com a sociedade. No Decreto oㅡ 52.062 de 2010, que regulamenta o artigo 50 da Lei no 14.223, a figura do Termo de Cooperação passa a ser usada pelas subprefeituras como instrumento para a criação e manutenção dos espaços públicos do município.

Das 483 áreas ajardinadas levantadas no mapa elaborado pela subprefeitura de Pinheiros em 2008, 66 possuem Termos de Cooperação firmados e mais 24 estão em

\footnotetext{
${ }^{3}$ Entrevista concedida em 15/07/2013.
} 


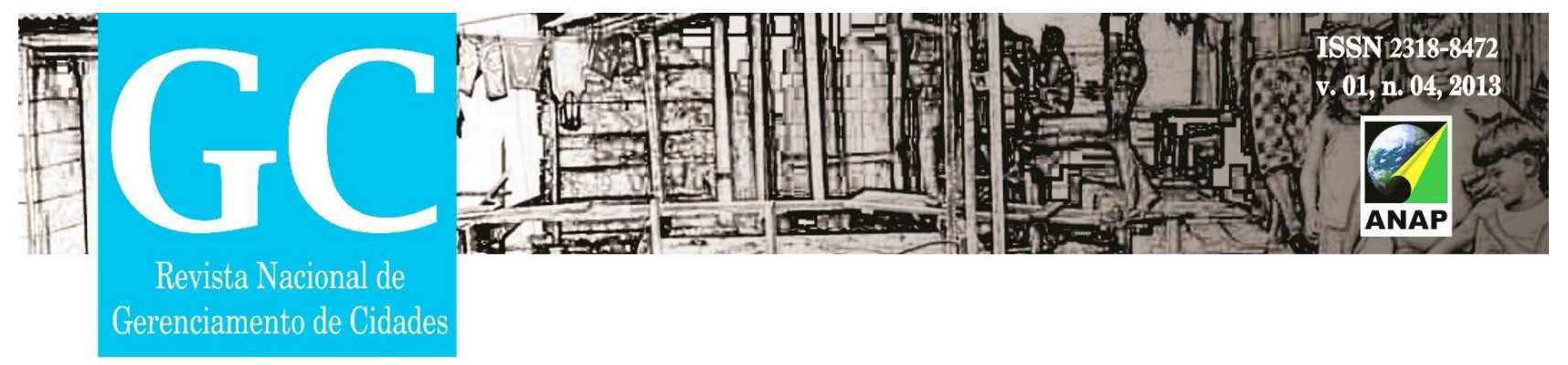

processo de assinatura ${ }^{4}$. Esses Termos de Cooperação são firmados entre a prefeitura, empresas, associações de moradores formalmente constituídas ou por cotização de moradores que fazem uma coleta mensal e se responsabilizam pela manutenção desse espaço. A validade desses termos pode variar de 12 a 36 meses, com exceção do que foi firmado em 2007 entre a prefeitura e a Editora Abril para a criação da Praça Victor Civita, que tem validade de 20 anos.

Verificar a existência da participação da sociedade na manutenção de espaços que a princípio deveria ser de inteira responsabilidade da administração pública não é fato conclusivo, mas aponta para a percepção de que a sociedade participa cada vez mais na gestão urbana.

Nesse sentido, praças que têm o envolvimento direto da comunidade em sua gestão como a Horácio Sabino, a Praça Guilherme Kawall, a Praça Coronel Pires de Andrade, a Praça Gastão Vidigal, e outras que têm termo de cooperação, refletem a melhoria propiciada por esse modelo de gestão compartilhada, maior grau de apropriação e comprometimento da população com seu uso.

Quanto à segurança que esses espaços públicos oferecem para os usuários o atual subprefeito de Pinheiros, arquiteto Angelo Salvador Filardo Junior afirma que:

Se a Praça é apropriada pela vizinhança ela tem um grau de uso, segurança e adequação muito maior. $O$ que se faz da praça responde ao que as pessoas querem dela. Às vezes uma praça está lá há muito tempo sem maiores demandas por parte do entorno porque as pessoas de fato não a usam, viraram as costas para ela, ergueram muros altos. Uma vez que as pessoas se apropriam da praça até o seu desenho pode ser mudado. A organização social faz o espaço na medida em que ela se fortaleça e se aproprie dele.

\section{CONSIDERAÇÕES FINAIS}

\footnotetext{
${ }^{4}$ Prefeitura de São Paulo:

<http://www.prefeitura.sp.gov.br/cidade/secretarias/subprefeituras/pinheiros/termo_de_cooperacao/index.php?p=30522> . Acesso em 24/08/2013. Atualizado por correspondência eletrônica com a subprefeitura de Pinheiros em 05/09/2013.
} 


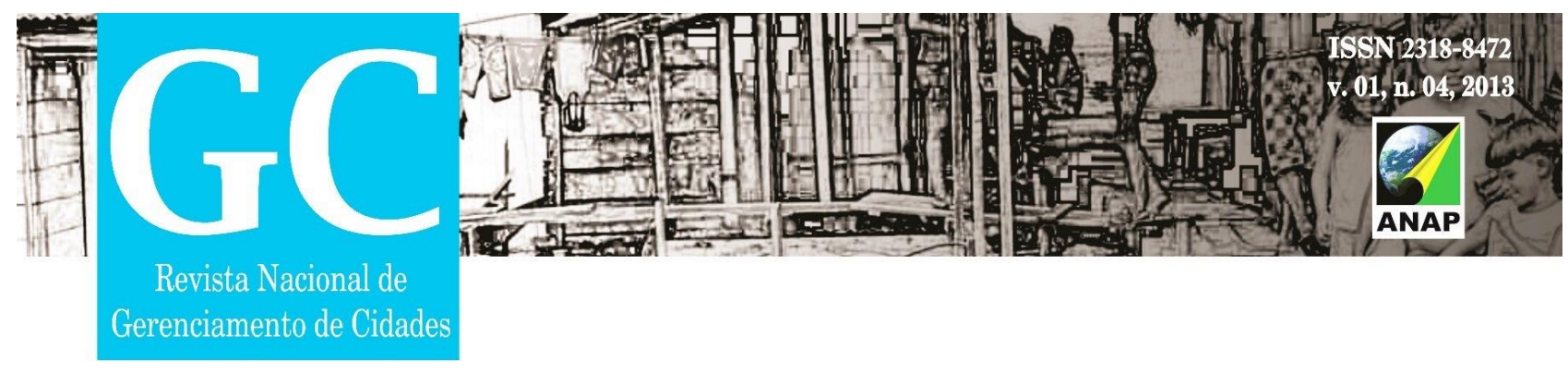

Com o levantamento realizado foi possível constatar que a subprefeitura tem 396 áreas sob sua responsabilidade com uma equipe pequena frente ao desafio de manter a qualidade de seus espaços púbicos. No entanto, a quantidade de Termos de Cooperação já é expressiva, com aproximadamente $19 \%$ das áreas sendo mantidas por meio da utilização de um instrumento que, aparentemente, gera maior apropriação do espaço público pela sociedade. Diante disso cabe ainda questionar se essa apropriação é causa ou consequência da atenção dada a esses espaços.

\section{REFERÊNCIAS}

ASCHER, François. Os Novos Princípios do Urbanismo. São Paulo: Romano Guerra; 2010.

CULLEN, Gordon. Paisagem Urbana. Lisboa, Edições 70, data não conhecida (tradução a partir da edição de 1984).

GEHL, Jan. Cities for People. Londres: Island Press, 2010.

JACOBS, Jane. Morte e vida de grandes cidades. São Paulo: Martins Fontes: 2000.

LEFEVRE, Henri. La production de l'espace. Paris: EconomicaEditions, 2000.

PREFEITURA DO MUNICÍPIO DE SÃO PAULO / PMSP. SUBPREFEITURA DE PINHEIROS / SP-PI (São Paulo, SP). Áreas Verdes SVMA SP-PI. São Paulo, 2008. 1 mapa. Sem Escala.

PREFEITURA DO MUNICÍPIO DE SÃO PAULO. SUBPREFEITURA DE PINHEIROS
(São Paulo, SP). Termo de Cooperação. Disponível em:
<http://www.prefeitura.sp.gov.br/cidade/secretarias/subprefeituras/pinheiros/termo_de_co
operacao/index.php?p=30522>. Acesso em 24/08/2013.

SANTOS, Milton. Espaço \& Método. São Paulo: Nobel, 1985.

SÃO PAULO (Município). Lei oㅜ 14.223, de 26 de setembro de 2006. Dispõe sobre a ordenação dos elementos que compõem a paisagem urbana do Município de São Paulo. Secretaria do Governo Municipal, São Paulo, SP, 26 set. 2006. Disponível em < http://cadan.prefeitura.sp.gov.br/sisgecan/downloads/Lei_14223_26.09.2006_PAISAGEN S_URBANAS.pdf>. Acesso em 10/08/2013. 


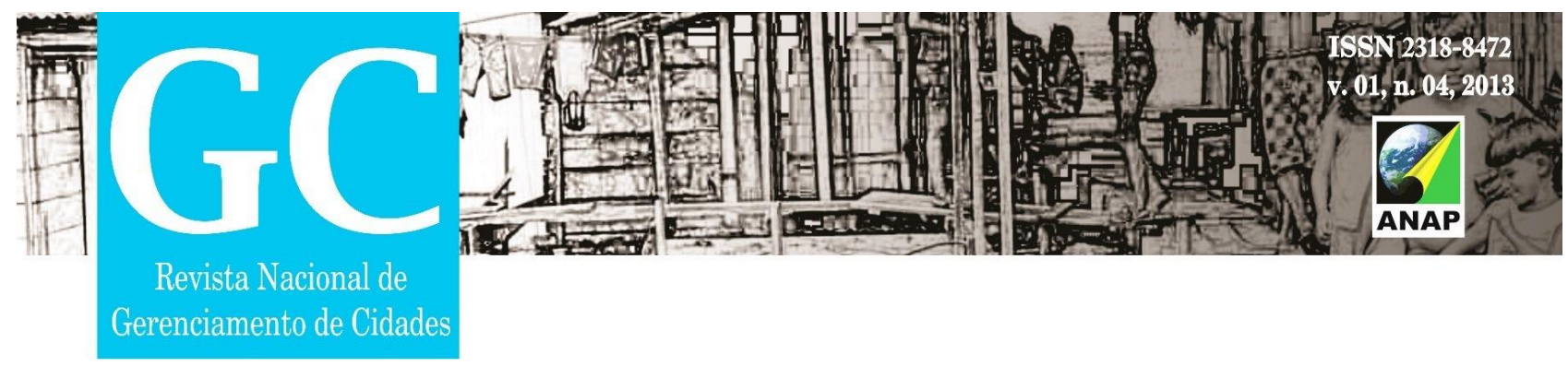

SÃO PAULO (Município). Decreto no 52.062, de 30 de dezembro de 2010. Dispõe sobre a celebração de termos de cooperação com a iniciativa privada, visando à execução e manutenção de melhorias urbanas, ambientais e paisagísticas, bem como à conservação de áreas municipais, em consonância com o disposto no artigo 24 da Lei no 14.517 , de 16 de outubro de 2007; acresce o $\S 3^{\circ}$ ao artigo $2^{\circ}$ do Decreto ํo 40.384, de 3 de abril de 2001, que dispõe sobre a doação de bens e serviços e o estabelecimento de parcerias com a iniciativa privada; revoga o Decreto o 50.077, de 6 de outubro de 2008. Diário Oficial [da] Cidade de São Paulo, São Paulo, SP, 31 dez. 2010. Ano 55, № 243, p. 3.

SEMPLA. Plano Diretor Estratégico do Município De São Paulo. São Paulo: Senac São Paulo, 2004.

SERPA, Angelo. O Espaço Público na Cidade Contemporânea. São Paulo: Contexto 2007.

WHYTE, William H.. The Social Life of Small Public Spaces. New York: Project for Public Spaces, 2001. 